\title{
Microwave-assisted convective drying of kale (Brassica oleracea L. var. sabellica L.) at stationary and non-stationary conditions
}

\author{
Mierzwa, D. ; Szadzińska, J.
}

Department of Process Engineering, Poznań University of Technology, Poznań, Poland

*E-mail of the corresponding author: dominik.mierzwa@put.poznan.pl

\begin{abstract}
This paper concerns hybrid drying of kale. Eight different schedules of drying were tested experimentally to find out the influence of microwave enhancement on the kinetics (drying rate and time), energy consumption of convective drying and quality of products. Different power of microwaves and modes of microwave application were tested. Quality of products was assesed through water activity and colour measurements, as well as retention of ascorbic acid. The results obtained in the studies allowed to state that intermittent application of high-power microwave pulses may lead to a meaningful reduction of drying time and high quality of the dry products.
\end{abstract}

Keywords: hybrid drying; intermittent drying; kale; ascorbic acid; colour 


\section{Introduction}

Kale (Brassica oleracea L. var. sabellica L.) is a common vegetable consumed in many countries, mainly in soups and salads. It may be described as a green headless leafy cabbage with long petioles and large midribbed leaves. Kale is recognized as a valuable source of many vitamins and nutrients. Moreover, kale is an excellent dietary source of natural antioxidants. Beneficial properties of Brassica vegetables have been attributed to the presence of bioactive compounds such as phenolic compounds and ascorbic acid, associated with a reduced risk of cardiovascular diseases and several types of cancer. ${ }^{[1]}$

Refrigeration and freezing are the easiest methods of food preservation. Regrettably, chilling of the raw material maintains acceptable characteristics only for a few days. On the other hand, freezing may cause significant sensory quality degradation. Besides, both refrigeration and freezing require a lot of energy which may not be accessible, especially in undeveloped countries. Drying is another method of food preservation. It is easier and less demanding in terms of apparatus construction. Ultimately, natural sun drying may be realized without any apparatus just with the use of solar radiation. Usually however, food products are dried by forced convection (with hot air) using various dryer designs (cabinet, tunnel, chamber, drum etc.). ${ }^{[2]}$

Unluckily, food processing may have both beneficial and detrimental effects on the phytochemicals in vegetables. ${ }^{[3]}$ Drying operation is usually accompanied by physical, biological and chemical changes, which influence the product quality, and finally the consumer choice. The main effect of drying is related with degradation of heat-sensitive phytochemicals, such as vitamins, antioxidants, minerals, pigments and other bioactive compounds. ${ }^{[4]}$ For these reasons, new drying technologies are sought to minimize the detrimental influence of this processing method on the products quality. The aim of this research was to analyse the influence of intermittent application of microwaves during convective drying on process kinetics, energy consumption and quality of products. Different modes of microwave enhancement and a changeable power of radiation were tested experimentally to determine their influence on the analysed parameters.

\section{Materials and Methods}

Fresh kale (Brassica oleracea L. var. sabellica L.) was bought on a local market and stored for at least $24 \mathrm{~h}$ under refrigeration at $4^{\circ} \mathrm{C}$. Before drying, $500 \mathrm{~g}$ of raw material was rinsed and cut into smaller pieces. Next, the samples were dried in a hybrid rotary dryer ${ }^{[5]}$ in eight different schedules (Table 1). 
Table 1. Description of the drying schedules.

\begin{tabular}{clcccc}
\hline No. & Code & Description & $\mathbf{T}\left({ }^{\circ} \mathbf{C}\right)$ & $\mathbf{v}(\mathbf{m} / \mathbf{s})$ & $\mathbf{P}_{\mathbf{m w}}(\mathbf{W})$ \\
\hline 1 & CV & convective drying & & & 0 \\
2 & CVMW1 & & & 100 \\
3 & CVMW2 & microwave-assisted conv. drying & & & 200 \\
4 & CVMW3 & 50 & 2 & 300 \\
5 & CVMW5 & & & 500 \\
6 & IT1 & & & $100-300$ \\
7 & IT2 & hybrid intermittent drying & & & $300-100$ \\
8 & IT3 & & & 1000 \\
\hline
\end{tabular}

All the CVMW programs were realized in stationary conditions - constant application of microwaves during convective drying. For the IT1 and IT2 programs, the microwaves were also applied continuously, but the MW power was reduced (from 300 to $100 \mathrm{~W}$ in IT1) or increased (from 100 to $300 \mathrm{~W}$ in IT2) by $10 \mathrm{~W}$ for every $10 \%$ of the weight loss. In the IT5 program, convection drying was supported periodically (for every 15 minutes) by highpower microwave impulses $(1000 \mathrm{~W})$ lasting $5 \mathrm{~min}$ each one. The effectiveness of drying schedule was assesed on the basis of its kinetics, energy consumption and product quality. The kinetics of particular process was analysed through comparison of drying curves - the evolution of moisture ratio (MR) in time, and the average values of drying time (DT) and rate (DR). The moisture ratio (MR) was designated by the following equation:

$$
M R=\frac{M C_{t}-M C_{e q}}{M C_{i}-M C_{e q}}
$$

where $\mathrm{MC}_{\mathrm{i}}, \mathrm{MC}_{\mathrm{t}}$, and $\mathrm{MC}_{\mathrm{eq}}$ are the initial, instantaneous (for a given time of the process) and equilibrium moisture contents.

The initial moisture content $\left(\mathrm{MC}_{\mathrm{i}}\right)$ of the material was determined with a moisture analyser (XM120; Precisa, Switzerland; precision $0.01 \%$ ). The equilibrium moisture content $\left(\mathrm{MC}_{\mathrm{eq}}\right)$ was assumed constant during the research and equalled 0.05 . The moisture content at a given time of the process $\left(\mathrm{MC}_{\mathrm{t}}\right)$ was expressed as the ratio of moisture mass to the initial mass of the wet sample. Energy consumption was measured with a standard electricity meter (precision $0.01 \mathrm{kWh}$ ) and recalculated to the MJ per gram of evaporated moisture (EC).

The product quality was assessed on the basis of colour, water activity, and ascorbic acid measurements. The colour of the fresh or dry material was measured with the use of colorimeter (CR400; Konica Minolta, Japan; precision 0.01). On the basis of the obtained CIE Lab tristimulus colour coordinates $\left(\mathrm{L}^{*}, \mathrm{a}^{*}\right.$, and $\left.\mathrm{b}^{*}\right)$, a relative colour change parameter (dE) was determined by: 


$$
d E=\left(d L^{* 2}+d a^{* 2}+d b^{* 2}\right)^{0.5}
$$

where $\mathrm{dL}^{*}, \mathrm{da}^{*}$ and $\mathrm{db}^{*}$ constitute differences between CIELab coordinates of fresh and dried samples.

Water activity (aw) was measured for both fresh and dried samples by using a laboratory meter (LabMaster-aw; Novasina, Switzerland; precision 0.001) at constant temperature of the chamber $\left(25^{\circ} \mathrm{C}\right)$. Ascorbic acid content was determined by the modified method ${ }^{[6]}$, with the use of spectrophotometer (UV 5100; Hitachi, Japan; precision 0.01). The absorbance was measured at the wavelength of $734 \mathrm{~nm}$, and next recalculated with the use of analytical curve. Next, the ascorbic acid loos (AL) was determined as:

$$
A L=\left(1-\frac{A C}{A C_{0}}\right) \cdot 100 \%
$$

where: $\mathrm{AC}_{0}$ and $\mathrm{AC}$ is the ascorbic acid content for fresh and processed sample, respectively.

\section{Results and discussion}

\subsection{Drying kinetics}

In Figure 1, the evolution of moisture ratio (MR) and the average drying rate (DR) for particular drying processes are presented.
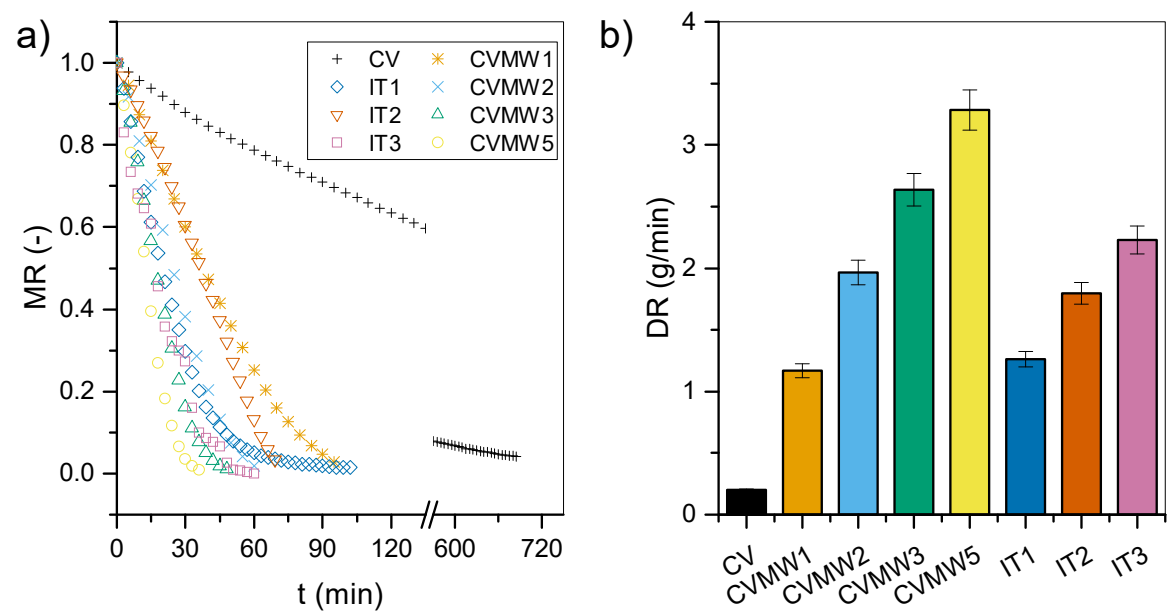

Fig. 1. a) evolution of the moisture ratio (MR) and b) average drying rate (DR) in particular drying processes. 
Application of MW during stationary processes (CVMW1-5), visibly affected the kinetics of convective drying (Fig. 1a). The higher MW power the faster drying rate (Fig. 1b) and shorter drying process as a consequence (Fig. 2a). In case of intermittent processes (IT1-3) the DR diminished noticeably, but the drying time was still significantly shorter than for CV. A comparison of IT1 and IT2 allows to state that starting with a higher MW power at the beginning of intermittent drying is more efficient than gradually increasing of MW power. Both drying rate and drying time were better for the IT2 program, where MW power was reduced from 300 to $100 \mathrm{~W}$ by $10 \mathrm{~W}$ for every $10 \%$ of the weight loss. Application of pulsed high-power microwaves during IT3 program positively influenced the kinetics of $\mathrm{CV}$. The drying rate was higher than in other nonstationary schedules and almost all stationary ones (Fig. 1b). It resulted in visibly shorter drying time (Fig. 2a).
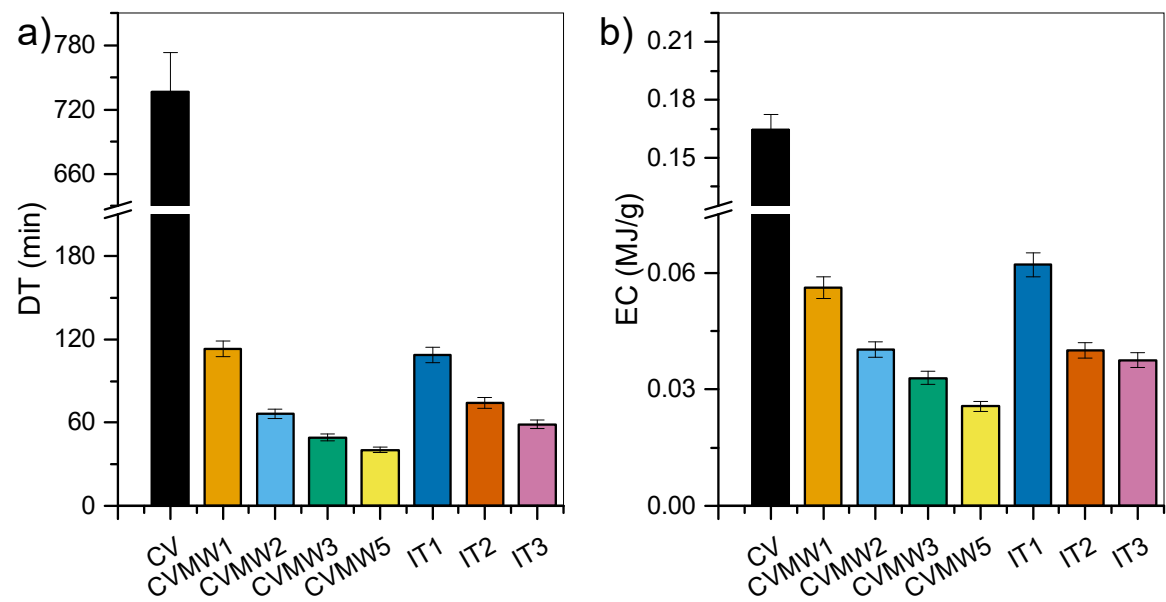

Fig. 2. Average values of a) drying time (DT) and b) energy consumption (EC).

Figure $2 \mathrm{~b}$ presents the average energy consumption for different drying schedules. One can see that application of microwaves during stationary (CVMW1-5) and nonstationary (IT13 ) processes affected the total energy consumption. The highest values of this parameter was observed for $\mathrm{CV}$, whereas the lowest one for CVMW5. Such results stay in good agreement with other kinetic parameters (DR and DT). It also implies that microwaves effectively improved the drying process of kale. The ineffective interaction of microwaves causes a negligible decrease in drying time, which connected with a larger instantaneous consumption of electricity (than for a purely convective operation), results in an increase in the total energy consumption.

\subsection{Quality of products}

In Figure 3, the average values of water activity (aw) and ascorbic acid loss (AL) are presented, respectively. 

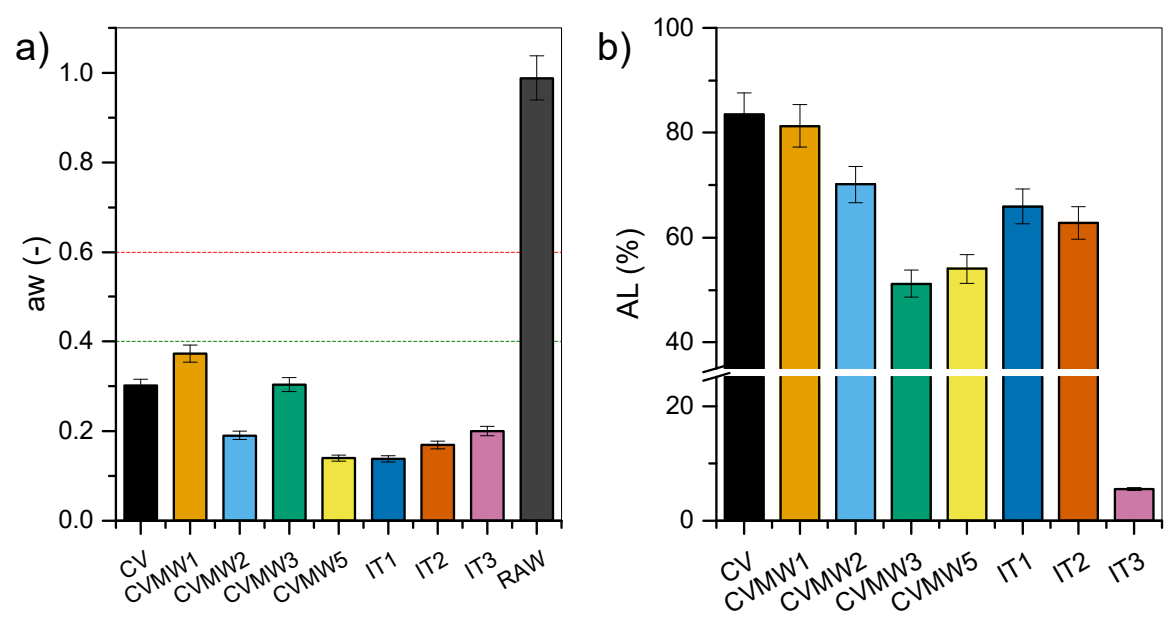

Fig. 3. Average values of the: a) water activity (aw) and b) ascorbic acid loos (AL).

It is generally assumed that if the processed product is characterized by aw below 0.6 it can be acknowledged as stable in terms of microbiological safety. ${ }^{[7]}$ All dry products obtained by different schemes were characterized by the aw below 0.4 , which means that there is no microbial proliferation. ${ }^{[8]}$ The analysis of the ascorbic acid loos (Fig. 3b) allows to state that all of the tested processes negatively affected retention of this valuable compound. The smallest leakage of ascorbic acid (below 10\%) was observed for IT3, where high-power impulses of MW were applied. It may result from the relatively short duration of drying and a small increase in the sample temperature. During this process, microwaves were applied only for 5 minutes, and then a 15-minutes the so-called relaxation period was introduced. The main aim of application of the relaxation period was to 'equalize' the material after intensive microwave drying. During this period, the temperature of samples decreased and the humidity distribution becomes more aligned. It surely resulted in milder drying conditions in comparison to severe stationary microwave-assisted convective processes (CVMW). Nevertheless, the ascorbic acid content in products dried by hybrid methods was higher than for solely convective process (CV). A small retention of ascorbic acid surely results from significantly longer drying time. Only in case of CVMW1, where the weakest microwave enhancement was applied $(100 \mathrm{~W})$, the amount of ascorbic acid was similar to $\mathrm{CV}$. Such result is quite unexpected and means that six-fold reduction in drying time did not affect the retention of the ascorbic acid present in dried products. 


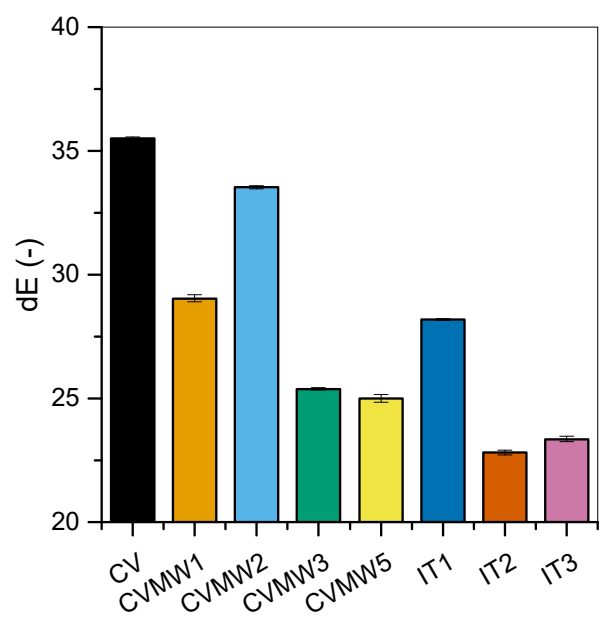

Fig. 4. Average values of the relative colour change (dE).

The last analysed parameter was colour of the dry products. Figure 4, shows the relative colour change $(\mathrm{dE})$. It can be seen, that all drying procedures influenced significantly the colour of the obtained products. Change in colour is mainly attributed to chlorophyll and carotenoids degradation. Chlorophyll is highly susceptible to degradation during processing and storage, and depends on temperature, $\mathrm{pH}$, time, enzyme, oxygen and light. Carotenoids have been proven to be more stable during thermal processing compared with chlorophylls, but may be isomerized and oxidized under the influence of heat, light and oxygen, and others. ${ }^{[9]}$ As expected, the highest value of relative colour change (dE) was observed for $\mathrm{CV}$, whereas the smallest values of this parameter were noticed for nonstationary processes, i.e. IT2 and IT3. It is a very positive effect because the reduction of MW radiation (in terms of both power and time) was aimed at this programs at the increase of the product quality. Interesting results were also observed for stationary schedules CVMW3 and CVMW5. Taking into account the progress of $\mathrm{dE}$ for CVMW1 and CVMW2, it was supposed to be higher for CVMW3 and CVMW5. Surprisingly, the value of dE decreased in these schedules which implies that colour of products depends on the drying time.

\section{Conclusions}

The continuous application of microwave radiation positively influences the kinetics of convective drying. The higher power of microwaves causes faster drying, shorter duration of the process and lower energy consumption. Unfortunately, microwave-assisted convective drying may negatively affect the quality of products. It was found that application of low power microwaves (100 and $200 \mathrm{~W})$ is not favourable in terms of colour and retention of ascorbic acid. The higher power of continuous microwave enhancement (300 and $500 \mathrm{~W}$ ) allows preserving both colour and ascorbic acid to a greater degree. 
Intermittent microwave-assisted drying can be an attractive alternative for both solely convective and stationary microwave-assisted convective processes. All kinetic and quality parameters attained values similar to those observed for stationary hybrid processes (CVMW). Additionally, it was found that the high-power microwave impulses very positively influence the retention of ascorbic acid.

\section{Acknowledgement}

This work was carried out as a part of research project No 03/32/DSPB/0805 founded by the Ponzań University of Technology.

\section{References}

[1] Podsędek, A. Natural antioxidants and antioxidant capacity of Brassica vegetables: A review. LWT - Food Science and Technology 2007, 40, 1-11.

[2] Mujumdar, A.S. Handbook of Industrial Drying; CRC Press: Boca Raton, 2015.

[3] Buena, A. et al. Total and individual carotenoids and phenolic acids content in fresh, refrigerated and processed spinach (Spinacia oleracea L.). Food Chememistry 2008, $108,649-656$.

[4] Devahastin, S.; Niamnuy, C. Modelling quality changes of fruits and vegetables during drying: A review. International Journal of Food Science \& Technology 2010, 45, $1755-1767$.

[5] Musielak, G.; Mierzwa, D.; Kroehnke, J. Food drying enhancement by ultrasound - A review. Trends in Food Science \& Technology 2016, 56, 126-141.

[6] Rutkowski, M.; Grzegorczyk, K. Modifications of spectrophotometric methods for antioxidative vitamins determination convenient in analytic practice. Acta Scientiarum Polonorum Technologia Alimentaria 2007, 6 (3), 17-28.

[7] Kahveci, K.; Cihan, A. Transport phenomena during drying of food materials. In Focus on Food Engineering Research and Developments; Pletney, V.N., Ed.; Nova Science Publishers Inc.: New York, 2007; 13-163.

[8] Tapia, M.S.; Alzamora, S.M.; Chirife, J. Effects of Water Activity (aw) on Microbial Stability: As a Hurdle in Food Preservation. In Water Activity in Foods: Fundamentals and Applications; Barbosa Cánovas, G.V., Fontana Jr., A.J., Schmidt, S.J., Labuza, T.P., Eds.; Blackwell Publishing Ltd.: Oxford, 2007; 239-271.

[9] Korus, A. Effect of Preliminary and Technological Treatments on the Content of Chlorophylls and Carotenoids in Kale (Brassica Oleracea L. var. Acephala). Journal of Food Processing and Preservation 2013, 37, 335-344. 